Session 392

\title{
Rejuvenating Electronic Technology Curricula to Match Industry Needs
}

\author{
Louis E. Frenzel Jr., Joseph S. Mattoon, PhD \\ Electronic Design Magazine/Maricopa Advanced Technology Education Center
}

There is evidence that curricula for AAS degree community college programs in electronics technology are lagging behind current industry practices. Recent studies indicate these programs are both deficient technically and skewed from what industry wants and needs. Rapid technological advancement plus economic and social changes over the past years have significantly altered the competencies and tasks for electronic technicians. Yet, community colleges continue to teach the "history of electronics" and often fail to include critical modern technology subjects that technicians need to know to be successful in today's electronics job market. Surveys of industry, colleges and textbook publishers indicate that community colleges do a good job of teaching the fundamentals, but much of the curriculum is still based on technology and job skills that are no longer relevant and valuable to employers. Furthermore, the subjects taught and the contexts in which they are presented do not appear to be aligned with current industry needs. The evidence that electronics curricula lags behind industry job skill needs and the advancement of new technology is discussed in more detail in a recent publication ${ }^{1}$ and by grant programs developed through the National Science Foundation ${ }^{2}$.

This paper verifies the problem by summarizing recent survey results and goes on to identify reasons for the variance between current curricula and industry practice. The paper suggests several possible solutions to the problem.

Scope of the Problem

The electronics industry changes faster than most people comprehend. New products, processes, and technologies are introduced daily. And because of the highly competitive nature of the electronics business, this new technology is rapidly adopted to create even newer and better electronic products and services. Good examples of rapid and continually changing electronic products are personal computers, cell phones, and consumer equipment like video games, DVD players, big screen plasma and LCD TV. In business and industry, the rapid adoption of new computer, networking, robotics and automation technologies has helped to bring about the massive increases in productivity reported over the past several years. ${ }^{3,4}$ Clearly, technicians are needed who are competent in and knowledgeable of these new technologies, because they must install, service, troubleshoot, maintain and operate the equipment.

"Proceedings of the 2004 American Society for Engineering Education Annual Conference \& Exposition Copyright () 2004. American Society for Engineering Education" 
Because of this rapidly changing technology, community and technical colleges are regularly challenged to supply Associate degree graduates who are not only fully steeped in the key principles of electronics but also knowledgeable of the latest components, circuits, equipment, and methods. Fortunately, there are numerous simple and low cost strategies and methods that colleges can adopt to update the curriculum without overburdening their faculty.

\section{Current Situation}

A recent survey ${ }^{5}$ of community college electronic programs revealed nine key problems with current programs. These problems and suggested solutions are outlined here.

Problem 1: Many community college courses and curricula are dated.

Solution 1: Recognize and accept the fact that most curricula and faculty experiences are well behind the current technology in industry. Form a committee to study and discuss the problem. Initiate actions to correct.

Problem 2: College curricula are difficult to change and update because of complex and restrictive department, college, state, and accrediting body policies.

Solution 2: While curriculum is difficult to change, it is relatively easy to update the courses by dropping dated material, adding new relevant topics, or changing textbooks.

Problem 3: $\quad$ Professors have little time or incentive to update courses.

Solution 3: $\quad$ Suggest that professors make one small manageable update in each course taught every time the course is offered.

Problem 4: Electronics textbooks are also out of date. ${ }^{6,9}$ A recent survey of electronic textbooks revealed enormous gaps in the coverage of modern components and circuits. It appears that if the most recent topics are not in the textbooks, the instructors do not teach them.

Solution 4: $\quad$ Solutions 2 and 3 can help with this problem. In addition, be proactive in providing feedback, recommendations and requests on content to the publishers. Discontinue using older long-used texts and seek out new and more up-to-date books.

Problem 5: Colleges cannot fully fund formal continuing education for faculty. Solution 5: Four ideas proven to solve this problem are:

a. Have faculty members with knowledge of specific topics teach other faculty in short informal sessions.

b. Make sure faculty has access to all relevant industry magazines.

c. Encourage faculty to pursue free on-line tutorials and other resources from professional societies (IEEE, ACM, ISA, etc.) and electronic companies.

d. Seek out and encourage industry summer internships locally.

"Proceedings of the 2004 American Society for Engineering

Education Annual Conference \& Exposition

Copyright (C) 2004. American Society for Engineering Education” 
Problem 6: Graduates are leaving college with critical gaps in their knowledge.

Industry wants a graduate who knows the essential fundamentals but also has knowledge of the most recent products and methods.

Solution 6: Revise and update your industry advisory board with new members. Such a change brings fresh new information and ideas. Ask for their recommendations and implement their suggestions.

Problem 7: Most electronic departments lack the funds needed to equip laboratories to teach the latest technologies.

Solution 7: Seek out simpler lower cost or older equipment that can provide some hands-on lab experiences. Ask for industry donations. Implement lab experiments with available simulation software.

Problem 8: The U.S. system of workforce development has no institutionalized process to update community and technical college programs on a national basis in coordination with industry.

Solution 8: Initiate a joint effort or help establish an agency responsible for providing a means of industry-college cooperation to synchronize workplace needs with college curricula. A good starting point is to work with other colleges in your region or state and through the ASEE's divisions that support the Conference for Industry and Education Collaboration (CIEC).

Problem 9: Electronic technology AAS degree enrollments have been decreasing for years. $5,8,9$

Solution 9: Through a college task force, attempt to quantify the decline and assess the future impact. Then with the help of the industry advisory committee, identify the reasons for the decline locally. Develop strategies to correct the problem.

An Unexpected Alternative

Most electronics technology curricula are relatively homogeneous across the country, and virtually all of the colleges have competently partitioned subject matter into appropriate courses. It is the course content that is the problem. The courses have the necessary core fundamentals, yet many dated and even obsolete subjects are still taught. One example is the overemphasis on bipolar transistors when most circuitry today is implemented with MOSFETs. The dated textbooks typically support this antiquated perception of the subject. The result is courses skewed toward a historical perspective rather than one of new technology and modern practice. Most courses could be easily updated by simply deleting or de-emphasizing selected topics and replacing them with newer, more relevant subject matter.

One exemplary effort to improve course content is being pursued via a National Science Foundation grant, recently funded to the Maricopa Advanced Technology Education Center (MATEC). The main goal of this grant is to develop a series of instructional 
modules that fill the gaps identified in electronics curricula by covering key hightechnology topics missing from the most popular electronics textbooks. Known by its formal title, Work-Ready Electronics: An Industry Supported System for Synchronizing Curriculum to the Rapidly Changing Workplace, the project is developing instructional modules that are delivered on-line. The modules incorporate a "learner-centered" approach that impels students and faculty to share the responsibility of keeping up to date with technology advancement. The modules provide full and relevant coverage of new and important topics that have been identified by industry representatives. These modules represent a hybrid form of instruction in which students gain most of their knowledge outside of class, then come together with their instructor for in-depth discussions of difficult concepts, followed by supervised hands-on practice and experimentation in the electronics laboratory.

Concise summaries of new topics, guided exercises, simulations and animations, lab experiments and on-line references give full and up-to-date coverage of each subject. Total module engagement time varies depending upon the scope and depth of the subject, but typical modules are designed for two to four hours of contact instruction and several hours of study and/or research outside of class. All or only specified parts of each module can be assigned by instructors as needed to accommodate course integration and scheduling.

Many activities involve team strategies that are practiced with other students to simulate work styles and job activities assigned by companies that employ technicians. Additional teaching and learning resources are also provided to support adoption of the modules. These include strategies for assisting teachers: integration plan for integrating module activities within extant courses (by excluding or decreasing outdated topics) and points on how to use the modules for effective teaching and tools that help students learn: a facility for electronic note-taking, on-line glossary of electronics terminology, and learning objectives that focus students on essential knowledge and skills and their relevance to current technician jobs.

With little investment in time, virtually any instructor can bring him or herself up to date on the subject matter with the module and teach it competently.

In summary, the modules have the following features and characteristics.

1. Module topics are derived from a combination of electronics industry research, industry recommendations collected from surveys, and suggestions from faculty.

2. The module topics are prepared to take into consideration the core concepts to be taught in the course and any necessary course prerequisites.

3. The modules recommend in which courses the topic may be taught and suggest what older and obsolete material can be omitted to make time for the new material.

4. The modules include relevant circuit simulations with suggestions for new laboratory equipment and software (e.g., Multisim) to ensure appropriate technician-level hands-on experience.

"Proceedings of the 2004 American Society for Engineering

Education Annual Conference \& Exposition

Copyright C 2004. American Society for Engineering Education” 
5. A major emphasis is on on-line research so that students learn what additional technical materials and education is freely available on the Internet via company web sites.

6. Complete assessment of learning (testing) is provided to ensure that learning objectives set by industry are met.

7. A fast and near-painless way to up date courses while simultaneously providing low time/cost continuing education of faculty is provided. Thus modules provide an evolutionary rather than revolutionary way to improve the technical and pedagogical viability of AAS programs.

Listed below are just some of the topics currently available and under development during the three-year period of the grant. These topics have been confirmed by industry input and agreement via the Emerging Electronics Curriculum Task Force (EECTF). However, a complete list of topics and requests for potential new topics is now under way to provide a more conclusive and better validated topic list. Electronics experts (especially those with current industry experience) are encouraged to visit the web site, review modules under development, and complete the new survey (link provided on the opening page) at www.work-readyelectronics.org

- $\quad$ Switching power supplies (regulators, DC-DC converters, inverters and UPS).

- Switching amplifiers (class D, E and F)

- Introduction to the electronic industry, jobs and careers.

- Difference between engineering and technology education.

- A frequency domain view of electronics using Fourier theory.

- Digital signal processing.

- Advanced analog-to-digital and digital-to-analog conversion.

- Battery technology and alternative energy sources

- Wiring and cabling technology.

- Advanced semiconductor memory, SDRAM, flash and others.

- Programmable logic devices (PLD).

- Modern MOSFET circuits and technology.

- System-level considerations for electronics for technicians.

- Phase-locked loop technology and applications.

- Frequency synthesis.

- Wireless technology fundamentals.

- Networking technology (Ethernet, SANs, Sonet/SDH).

\section{Bibliography}

1. $\quad$ Frenzel, Louis E., The Disappearing Associate Degree Program in Electronics Technology, 2003 American Society for Engineering Education Annual Conference and Exposition, Nashville, TN.

2. NSF. (2003). Advanced technological education: Program solicitation. National Science Foundation [on-line], Available: http://www.ehr.nsf.gov/due/programs/ate/

"Proceedings of the 2004 American Society for Engineering Education Annual Conference \& Exposition Copyright (C) 2004. American Society for Engineering Education” 
3. Moritsugu, Ken, Surging productivity reduces need to hire, Knight Ridder News Service, November 6, 2003.

4. Dobbs, Lou, The perils of productivity, U.S. News \& World Report, November 10, 2003.

5. Enrollment Decline Survey: Electronic Technology, Engineering Technology Division (ETD) Listserve, December 2002.

6. Literature Review of Electronic Technology Textbooks, Maricopa Advanced Technology Education Center, NSF grant proposal 02-035, 2002.

7. Lewin, T., When Books Break the Bank. The New York Times, September 16, 2003 [on-line], Available: http://www.nytimes.com.

8. $\quad$ Science and Engineering Indicators 2002, National Science Board.

9 Cyberstates 2003: A State-By-State Overview of the High-Technology Industry, November, 2003, American Electronics Association.

\section{Biographies}

Louis E. Frenzel Jr. has 25+ years of electronic industry experience as well as 9+ years of teaching experience in community college electronic programs. He helped start the semiconductor manufacturing technology (SMT) program at Austin Community College and served as the first Department Head. Mr. Frenzel is currently employed as a Technology Editor for Electronics Design magazine. He is author of 18 books on electronic and computer subjects. His education includes an AAS degree from Capitol College (formerly CREI), a Bachelor's degree in Electronics Technology from the University of Houston and a Master's degree in Education from the University of Maryland.

Joseph Mattoon earned a B.A. in Fine Art from the University of California at Berkeley in 1982 and a Ph.D. in Educational Technology from Arizona State University in 1994. Joseph worked for the Air Force Research Laboratory from 1988 to 1997 as a Research Psychologist and for Science Applications International Corporation from 1997 to 2000 as a Training Specialist and Human Factors Engineer. In July 2000 he joined the Maricopa Advanced Technology Education Center (MATEC). He is currently Principle Investigator for the Work-Ready Electronics grant. His major interest is combining cognitive and behavioral theory with instructional design and technical pedagogy. 